\title{
EFFECT OF THYME OIL ON DOXORUBICIN-INDUCED HEPATOTOXICITY IN FEMALE ALBINO RATS: HISTOLOGICAL, ULTRASTRUCTURAL, AND BIOCHEMICAL STUDIES
}

\author{
Eman H. Kandil*; Yosry A. Okdah; Ayat G. Moselhy \\ Zoology Department, Faculty of Science, Menoufia University, Menoufia, Egypt
}

Article History:
Received: 23 July 2021
Revised: 23 August 2021
Accepted: 25 August 2021
Published Online:
9 September 2021
Keywords:
Aminotransferases
Antioxidants
Doxorubicin
Electron microscope
Thyme oil
*Correspondence:
Eman H. Kandil
Zoology Department
Faculty of Science
Menoufia University
Menoufia, Egypt
E-mail:
emanhosney88@yahoo.com

Article History:

Received: 23 July 2021

Revised: 23 August 2021

Accepted: 25 August 2021

Published Online:

Keywords:

Aminotransferases

Antioxidants

Doxorubicin

Electron microscope

*Correspondence:

Eman H. Kandil

Zoology Departmen

Faculty of Science

Menoufia University

E-mail:

emanhosney88@yahoo.com

\begin{abstract}
The limited usage of doxorubicin in chemotherapy returns to its toxicity on different organs. Thyme oil has antioxidant, antiinflammatory, and anticancer activities. This study aimed to investigate the alleviative effect of thyme oil on doxorubicininduced hepatotoxicity in rats. Twenty adult female albino rats (Rattus norvegicus) were randomly divided into four groups (5 rats/group): control group, thyme group received orally $0.5 \mathrm{~mL}$ thyme oil $/ \mathrm{kg}$ body weight once/week for 6 consecutive weeks, doxorubicin group received intraperitoneally $2 \mathrm{mg}$ doxorubicin/kg body weight once/week for 6 consecutive weeks, and "doxorubicin+thyme" group received both doxorubicin and thyme oil once/week for 6 consecutive weeks. Alteration in the liver ultrastructure and changes in the activities of serum aminotransferases and antioxidant enzymes were estimated in the current study. Liver histology of doxorubicin-treated rats showed congested blood vessels, masses of inflammatory leucocytic infiltration, and cytoplasmic vacuolation and pyknotic nuclei of the liver cells. Liver ultrastructure of doxorubicin-treated rats showed vacuolated and rarified cytoplasm, enlarged ruptured mitochondria, and large number of lysosomes. The rough endoplasmic reticulum lost most of its ribosomes, and its cisternae were unparalleled, as well as the nuclear envelope was mild tortuous. In addition, the aminotransferases (ALT and AST) activities and MDA level were increased significantly; while the antioxidant enzymes (SOD and CAT) activities were decreased significantly in the doxorubicin-treated animals compared with the control group. In the current study, thyme oil ameliorated most of the hepatotoxic effects of doxorubicin in rats. Therefore, thyme oil can be used as adjunct therapy to reduce doxorubicin toxicity.
\end{abstract}

\section{INTRODUCTION}

Cancer became a very serious health problem in both developed and developing countries. Lung cancer is the most cause of death in males, while breast cancer has the highest mortality among females ${ }^{[1]}$. There are different strategies in tumor treatment like removal by surgery, radiotherapy, chemotherapy, hormonal therapy, and immunotherapy ${ }^{[2]}$. In chemotherapy, drugs and medications are used to either control or destroy tumor cells. They can be used alone 
or in combination with other strategies ${ }^{[3]}$. Chemotherapeutic drugs are divided into alkylating agents, antimetabolites, antitumor antibiotics, cytotoxic antibiotics, antimicrotubule agents, and topoisomerase inhibitors according to their chemical structure and mechanisms of their action ${ }^{[2]}$.

Anthracyclines (such as doxorubicin) are antibiotics derived from Streptomyces peucetius bacteria. These compounds have not only antimicrobial properties, but also antitumor characters. This type of drugs works by causing damage to DNA through inducing topoisomerase II dependent DNA cleavage, intercalating with DNA double helix, and inhibiting DNA polymerase ${ }^{[2]}$. Doxorubicin is effective in therapy of different cancer types such as acute leukemia $^{[4]}$, many types of carcinomas (solid tumors) ${ }^{[5]}$, and lung cancer ${ }^{[6]}$. It affects healthy cells and cancer cells, like any other chemotherapeutic drugs. Much research has reported its toxicity such as cardiotoxicity ${ }^{[7]}$, renal toxicity ${ }^{[8]}$, hepatotoxicity ${ }^{[9]}$, genotoxicity ${ }^{[10]}$, testicular toxicity ${ }^{[11]}$, and neurotoxicity ${ }^{[12]}$. Doxorubicin increased the oxidative stress in tissue that was noticed by increasing malondialdehyde (MDA) and nitrogen oxide levels and decreasing the glutathione peroxidase, total superoxide dismutase, manganese superoxide dismutase (SOD), and catalase (CAT) activities, as well as glutathione level and total antioxidant capacity ${ }^{[13]}$.

The use of substance or compounds with antioxidant capacity and or scavenger activity of free radicals may decrease the side effect or restore the normal architecture of different organs after doxorubicin treatment. The best way to do that is the return to primitive, and uses plants from nature; such plants are rich in many biological compounds that have different properties as antibacterial, antiviral, antidiabetic, anti-inflammatory, etc. Thyme (Thymus vulgaris) is a traditional plant, which was used for the treatment of several inflammatory respiratory diseases like asthma and bronchitis ${ }^{[14]}$. Thyme belongs to Lamiaceae family. Like other members of the Lamiaceae family, thyme and its oil composed of aromatic bioactive compounds and their secondary metabolites have antioxidant (that scavenger free radical ${ }^{[15]}$, anti-inflammatory ${ }^{[16]}$, antimicrobia ${ }^{[17]}$, and anticancer activities ${ }^{[18]}$. Analyzing thyme essential oil by using gas chromatographyspectrometry mass and gas chromatography with flame ionization detection revealed the presence of linalool $(72.5 \%)$, thymol $(41.0 \%)$, thujanol $(42.2 \%$ cis-sabinene hydrate and $7.3 \%$ trans-sabinene hydrate), and geraniol $(26.4 \%)$, as well as contains borneol and carvacrol ${ }^{[19]}$. Therefore, the present study aimed to investigate the alleviative effect of thyme oil on doxorubicin-induced hepatotoxicity in rats with emphasize on the liver architecture and serum biochemicals.

\section{MATERIAL AND METHODS \\ Drug}

Doxorubicin (CAS number: 25316-40-9) ampoule $(10 \mathrm{mg})$ produced by Carlo Erba (Barcelona, Spain). It was purchased from a local pharmacy in Shebin El-Kom, Menoufia Governorate, Egypt. Rats were intraperitoneally injected with $2 \mathrm{mg} / \mathrm{kg}$ body weight $^{[20]}$.

\section{Thyme Oil}

Thyme oil (CAS number: 8007-46-3) bottle $(30 \mathrm{~mL})$ was obtained from local natural herb shop in Shebin El-Kom, El Captain Company (CAP PHARM) for extraction natural oils, plants, and cosmetics (license of ministry of health number 33/2006). Animals were orally given a dose of $0.5 \mathrm{~mL} / \mathrm{kg}$ body weight ${ }^{[21]}$.

\section{Experimental design}

Twenty adult female albino rats (Rattus norvegicus, three-month-old, weighing $120 \pm$ $5 \mathrm{~g})$ were used in the current study. Animals were randomly/equally divided and put in plastic rodent cages in an air-conditioned animal house, at $25 \pm 2^{\circ} \mathrm{C}$ and under lightdark cycle (12/12), at least for one week before starting the experiment for acclimatization. Animals received standard rodent diet and were given free access to food and water. This study and all experiments 
followed the procedures of the Animal Care and Bioethics of the Egyptian Committee, and the animal work was done at Faculty of Science, Menoufia University (Approval number, MNFS H120). The animals were randomly divided (5 rats/each group) into:

1. Control group: Animals of this group were administered orally with distilled water, and intraperitoneally with saline.

2. Thyme-treated group was orally given thyme oil at a dose of $0.5 \mathrm{~mL} / \mathrm{kg}$ body weight, once/week for 6 consecutive weeks.

3. Doxorubicin-treated group was injected intraperitoneally with doxorubicin at a dose of $2 \mathrm{mg} / \mathrm{kg}$ body weight, once/week for 6 weeks. It is diluted with saline immediately before use.

4. Doxorubicin+thyme-treated group were injected intraperitoneally with $2 \mathrm{mg}$ doxorubicin/kg body weight followed by oral administration of $0.5 \mathrm{~mL}$ thyme oil $/ \mathrm{kg}$ body weight once/week for 6 consecutive weeks. At the end of the $6^{\text {th }}$ week of the experiment, rats were anesthetized with halothane, dissected, and livers were removed.

\section{Histological investigation}

Liver specimens were cut into small pieces, fixed in $10 \%$ neutral formalin for normal histological study, stained with hematoxylin and $\operatorname{cosin}^{[22]}$, examined, and photographed by Olympus microscope (BX41TF, Olympus Corporation, Shinjuku City, Tokyo, Japan).

\section{Ultrastructural examination}

Pieces from liver (not more than 1-2 mm in thick) were fixed in glutaraldehyde and prepared to be examined and photographed by transmission electron microscope ${ }^{[23]}$ using JEM-1400 Plus (JEOL Ltd., Akishima, Tokyo, Japan), at Alexandria unite for electron microscope, Faculty of Science, Alexandria University (Alexandria, Egypt).

\section{Biochemical Analysis}

For biochemical parameters assay, animals were fasted for 16-18 hours, then killed by cutting the neck at the jugulars by a sharp razor blade after anesthetized with halothane.
The blood sample from each animal was collected separately into a sterilized tube and left at room temperature for coagulation to separate serum for evaluating the following different biochemical markers: aspartate aminotransferase (AST), alanine aminotransferase $(\mathrm{ALT})^{[24]}, \mathrm{MDA}^{[25]}, \mathrm{SOD}^{[26]}$, and $\mathrm{CAT}^{[27]}$.

\section{Data evaluation and statistical analysis}

The data were expressed as mean \pm standard error. Data were analyzed by using statistical program of social science (SPSS) software for windows V17 (SPSS, 1999). The means were compared by significant difference test $(t$-test $)$. The values are significant when $P$ value is less than 0.05 .

\section{RESULTS}

Thyme oil alleviated alterations in serum aminotransferases activities in doxorubicin-treated female rats

There is a significant increase $(P<0.05)$ in serum ALT and AST activities in the doxorubicin-treated animals compared with the control animals (Table 1). Thyme oil alone did not induce a significant change in serum ALT and AST activities. On the other hand, a significant decrease $(P<0.05)$ in serum ALT and AST activities was recorded in animals treated with doxorubicin +thyme oil in comparison to doxorubicintreated animals (Table 1).

Thyme oil alleviated alterations in serum MDA levels and SOD and CAT activities in doxorubicin-treated female rats

Doxorubicin caused a significant increase $(P<0.05)$ in malonaldehyde (a lipid peroxidation marker) level and a significant decrease in activities of the antioxidant enzymes "SOD and CAT" when compared with the control group (Table 2). Thyme oil alone did not induce a significant change in these parameters. On the other hand, a significant decrease $(P<0.05)$ in serum level of MDA and a significant increase $(P<0.05)$ in serum SOD and CAT activities were found in animals treated with doxorubicin+thyme oil compared with doxorubicin-treated animals (Table 2). 
Table 1: Effects of thyme oil on serum ALT and AST activities in doxorubicin-treated female albino rats.

\begin{tabular}{lll}
\hline & ALT $(\mathrm{U} / \mathrm{L})$ & AST $(\mathrm{U} / \mathrm{L})$ \\
\cline { 2 - 3 } Control & $18.60 \pm 0.29$ & $21.40 \pm 0.51$ \\
Thyme Oil & $19.20 \pm 0.62$ & $23.00 \pm 0.71$ \\
Doxorubicin & $54.80 \pm 0.53^{*}$ & $60.00 \pm 1.22^{*}$ \\
Doxorubicin+Thyme Oil & $33.60 \pm 0.84 \#$ & $37.40 \pm 0.53 \#$ \\
\hline
\end{tabular}

Data were expressed as mean \pm standard error $(n=5)$. ALT: alanine aspartate aminotransferase, AST: aspartate aminotransferase. ${ }^{*} P<0.05$ compared to the control group, $\# P<0.05$ compared to the doxorubicin-treated group.

Table 2: Effects of thyme oil on serum CAT and SOD activities and MDA level in doxorubicin-treated female albino rats.

\begin{tabular}{lccc}
\hline & $\begin{array}{c}\text { CAT } \\
(\mu \mathrm{mol} / \mathrm{second} / \mathrm{mL})\end{array}$ & $\begin{array}{c}\text { SOD } \\
(\mathrm{nmol} / \mathrm{mL})\end{array}$ & $\begin{array}{c}\text { MDA } \\
(\mathrm{nmol} / \mathrm{mL})\end{array}$ \\
\cline { 2 - 4 } Control & $27.00 \pm 0.77$ & $88.85 \pm 0.51$ & $4.77 \pm 0.08$ \\
Thyme Oil & $32.80 \pm 0.73$ & $92.60 \pm 0.45$ & $5.42 \pm 0.12$ \\
Doxorubicin & $15.80 \pm 0.58^{\star}$ & $42.00 \pm 0.79^{\star}$ & $12.80 \pm 1.27^{\star}$ \\
Doxorubicin+Thyme Oil & $24.20 \pm 0.84 \#$ & $77.90 \pm 0.75 \#$ & $4.21 \pm 0.07 \#$ \\
\hline
\end{tabular}

Data were expressed as mean \pm standard error $(n=5)$. CAT: catalase, SOD: superoxide dismutase, MDA: malondialdehyde. ${ }^{*} P<0.05$ compared to the control group, $\# P<0.05$ compared to the doxorubicin-treated group.

Thyme oil alleviated histological alterations in liver sections of doxorubicintreated female rats

Sections from liver of control rat showed normal lobular architecture. The hepatic cells were arranged in strands around the central vein and separated from each other by sinusoid (Figure 1a). The sinusoids are narrow blood spaces with irregular boundaries composed of: first, a single layer of fenestrated endothelial cells; second, Kupffer cells are phagocytic cells extending into the lumen of the sinusoids (Figure 1a). The hepatocytes are polygonal in shape with acidophilic cytoplasm and each cell has large round nuclei with one or two nucleoli (Figure 1a). Few cells are bi-nucleated. Branches of the portal vein, the hepatic artery, and the hepatic ductile are found in portal space. The bile ductule appears rounded or obliged in shape according to the plane of sectioning. It is lined by a layer of cuboidal cells and encircled by a thin sheath of connective tissue. Liver obtained from rats treated with thyme oil for six weeks also exhibited the normal structure as in the control group (Figure 1b).

On the other hand, after 6 weeks of treatment with doxorubicin, intensive changes noticed in the liver sections when examined by light microscope. The hepatic architecture was lost and congested blood vessels, masses of leucocytic infiltration, balloon shaped cell, and pyknotic nuclei were also observed (Figure 1c). Figure "1d" showed enlargement in the portal vein and sinusoids, and proliferated bile ductile in the liver of the doxorubicin group. Macro and micro nuclei were also noticed in the liver of the doxorubicin group. (Figure 1e). Rats treated with doxorubicin+thyme for 6 weeks showed an improvement in the hepatic architecture, almost hepatocytes are ordinary in shape, but some still less degenerated (Figure 1f). Most of the nuclei appeared normal, Kupffer cells retain its shape, and the widen in the blood sinusoids is disappeared in the doxorubicin+thyme group. 

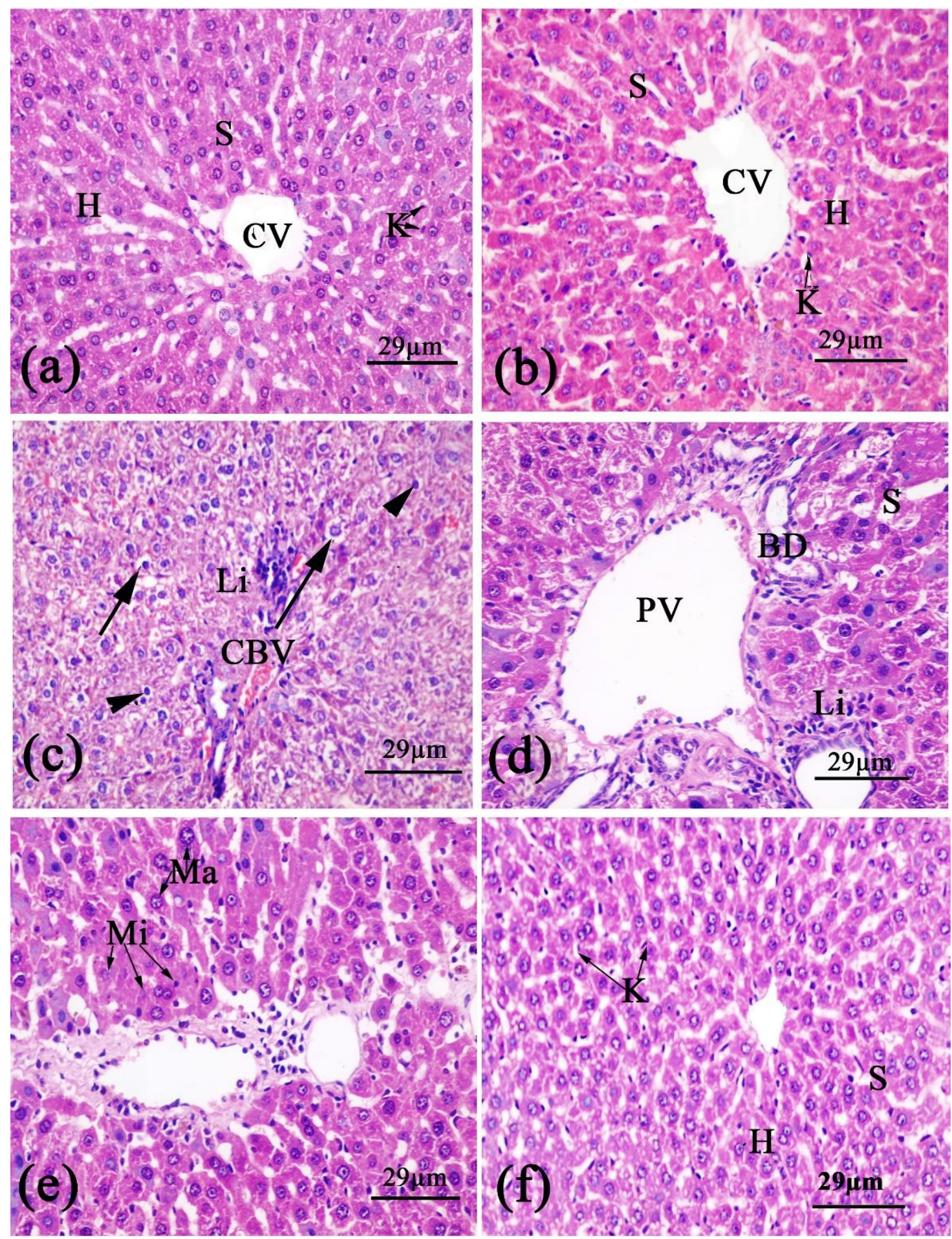

Figure 1: Photomicrographs of rat liver sections of (a) control rat showing central vein (CV), hepatocyte $(\mathrm{H})$, blood sinusoids $(\mathrm{S})$, and Kupffer cells $(\mathrm{K})$; (b) rat treated with thyme oil for 6 weeks showing normal hepatic cell $(\mathrm{H})$ around central vein $(\mathrm{CV})$, blood sinusoids $(\mathrm{S})$, and Kupffer cells $(\mathrm{K})$; (c) rat treated with doxorubicin for 6 weeks showing congested blood vessels $(\mathrm{CBV})$, leucocytic infiltration (Li), cytoplasmic vacuolation (arrows), pyknotic nuclei (arrows head); (d) rat treated with doxorubicin for 6 weeks showing enlarged portal vein (PV), bile ductule proliferation (BD), widen sinusoids (S), and inflammatory leucocytic infiltration (Li); (e) rat treated with doxorubicin for 6 weeks showing macro (Ma) and micro (Mi) nuclei; (f) rat treated with doxorubicin+thyme oil for 6 weeks showing an improvement in the hepatic architecture. 
Thyme oil alleviated ultrastructural alterations in the liver of doxorubicintreated female rats

Ultrastructurally, the hepatocytes of control animals appeared polygonal in shape with one nucleus (Figure 2a) or two nuclei (Figure 2b). The nuclei are spherical with prominent nucleolus and regular nuclear envelope consisting of two regular parallel distinct nuclear membrane that contained distinguished pores. The distribution of chromatin content appeared normal. The hetero chromatin was typically concentrated as small irregular clumps along the periphery of the nucleus with only a few hetero chromatin aggregations scattered in the karyoplasm. The outer membrane of the nuclear envelope was marginated by clusters of granules, ribosomes and polyribosomes, and is continuous with rough endoplasmic reticulum (Figure 2a,b).
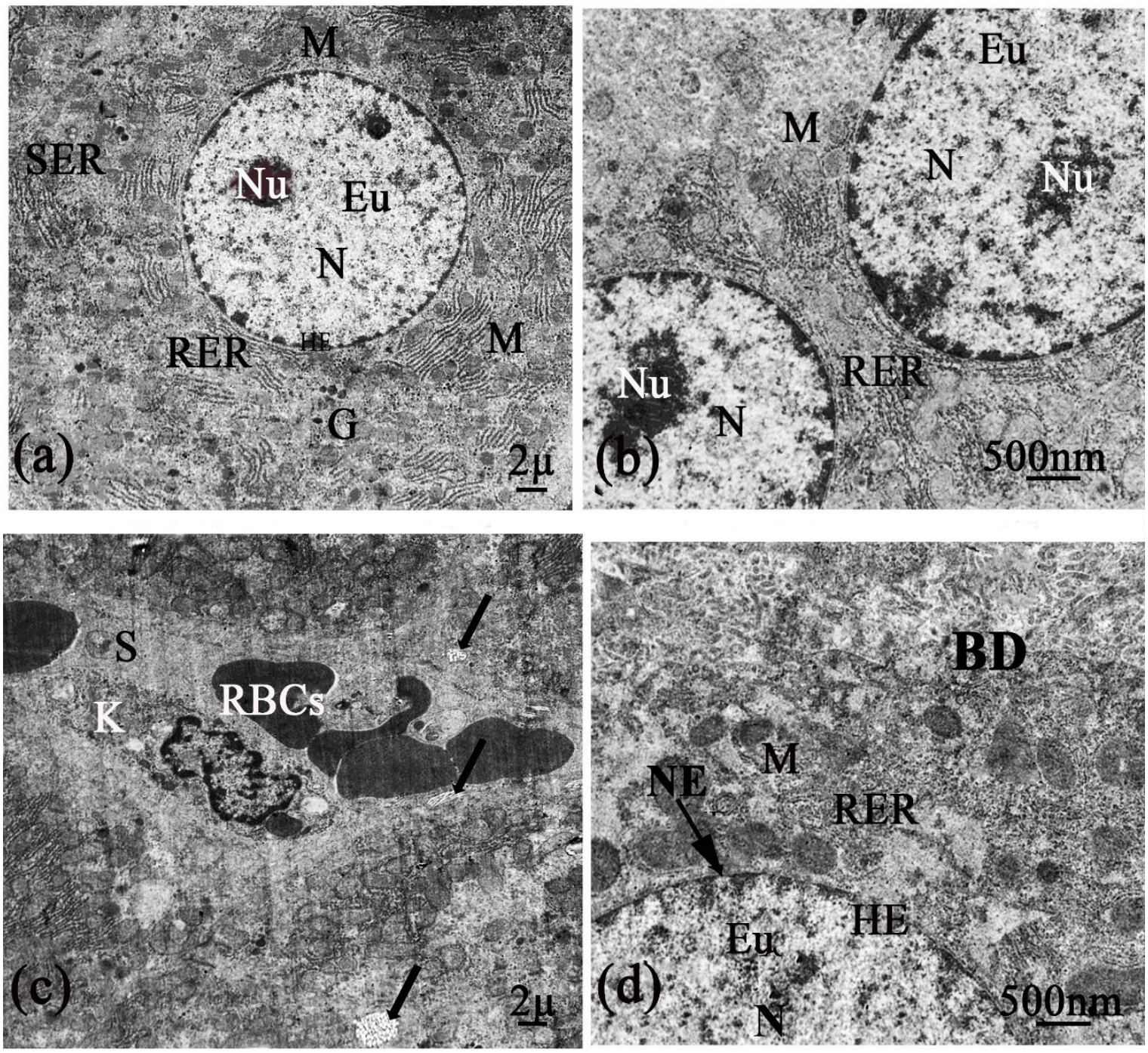

Figure 2: Electron micrographs of rat hepatocytes of control group showing (a) normal hepatocyte with parallel flattened cisternae of rough endoplasmic reticulum (RER), smooth endoplasmic reticulum (SER), normal mitochondria (M), ordinary glycogen granules (G) and normal rounded nucleus $(\mathrm{N})$ with prominent nucleolus $(\mathrm{Nu})$ (b) binucleated hepatocyte, (c) part of normal hepatocyte and blood sinusoid (S) with red blood corpuscles (RBCs) and Kupffer cell (K) having irregular nucleus. Notice the presence of collagen (thick arrow); (d) thyme oil-treated group showing normal appearance of hepatocyte; large, rounded nucleus (N) with abundant euchromatin (EU), heterochromatin (HE) and normal nuclear envelop (NE), normal rough endoplasmic reticulum (RER), normal mitochondria (M), and bile ductule (BD). 
The cytoplasm is crowded with organelles; particularly rough endoplasmic reticulum, smooth endoplasmic reticulum, well organized mitochondria of variable shapes and sizes, Golgi apparatus, and glycogen particles (Figure 2a,b). In Figure "2c" blood sinusoid appeared containing red blood cells and Kupffer cells, which have irregular nucleus. Also, collagen fiber is observed. Liver ultrastructure of animals treated with thyme oil showed normal hepatocytes with normal nucleus and one nucleolus, normal rough endoplasmic reticulum, and mitochondria scattered in the cytoplasm (Figure 2d).

Different ultrastructural changes in hepatocytes were observed after treatment with doxorubicin for 6 weeks. The hepatic cytoplasm is vacuolated, rarified, and contains enlarged ruptured mitochondria, damaged and unparalleled cisternae of rough endoplasmic reticulum, large number of lysosomes, and broken (not continuous) microvilli of bile ductule (Figure 3a-c). The nuclear envelope is mild tortuous and the rough endoplasmic reticulum lost most of its ribosomes (Figure 3c). Figure "3d" showed binucleated hepatocyte with two polymorphic nuclei, one large and adequate normal and the second was small and pyknotic with condensed chromatin; the mitochondria are swollen with destroyed cristae. Figure " $3 \mathrm{e} "$ showed secondary lysosomes and degenerated mitochondria. Part of sinusoids with RBCs as well as part of hepatic cell with pyknotic nucleus, appeared in Figure " $3 \mathrm{f}$ ".

An improvement was noticed in the liver of the group of animals treated by doxorubicin+thyme, the hepatocyte ultrastructure almost returned to normal (Figure 4a,b). Normal rounded nucleus with ordinary hetero chromatin and euchromatin content, normal rough endoplasmic reticulum, and rosette shape of glycogen granules were seen in the doxorubicin+thyme-treated group, the mitochondria were also normal in size and shape (Figure 4a,b).

\section{DISCUSSION}

Doxorubicin is an anthracycline antibiotic used in cancer treatment, but its relatively high toxicity limits its usage. Regarding the biochemical results of the current study, treating rats with doxorubicin caused a significant increase in serum ALT and AST activities. The increase in the serum AST and ALT activities after doxorubicin is attributed to their leakage from damaged and necrotic hepatocytes because the drug toxicity stimulates the formation of the reactive oxygen species ${ }^{[28]}$. Sakr and Abo-El-Yazid ${ }^{[29]}$ found also that ALT and AST were increased in the sera of doxorubicin-treated rats. Reactive oxygen species formation might increase membrane oxidized fats and protein damage in the liver by promoting lipid peroxidation of the cell membrane, which could result in elevated membrane fluidity and cell death ${ }^{[30]}$. In the present study, there was a significant decrease in the level of serum antioxidant enzymes (CAT and SOD) activities and a significant increase in serum MDA level in doxorubicin-treated animals. These changes in the antioxidant enzymes concentration may be related to the free radical formation. Other studies reported that doxorubicin induced a reduction in antioxidant defenses ${ }^{[29,31-32]}$.

Concerning the histological results, liver sections from doxorubicin-treated rats showed congested blood vessels, masses of inflammatory leucocytic infiltration, cytoplasmic vacuolation and necrotic nuclei, enlargement in portal vein and sinusoids, and proliferated bile ductule. Macro and micro nuclei were also noticed in liver of doxorubicin-treated rats. These histological changes are attributed to the chemical structure of doxorubicin that causes release of free radicals and the induction of oxidative stress that related to cellular injury ${ }^{[28,33]}$. Nuclear alteration caused by doxorubicin may be due to the intercalation of doxorubicin with DNA leading to inhibition of topoisomerase-II activity, the formation of DNA single and double strand 

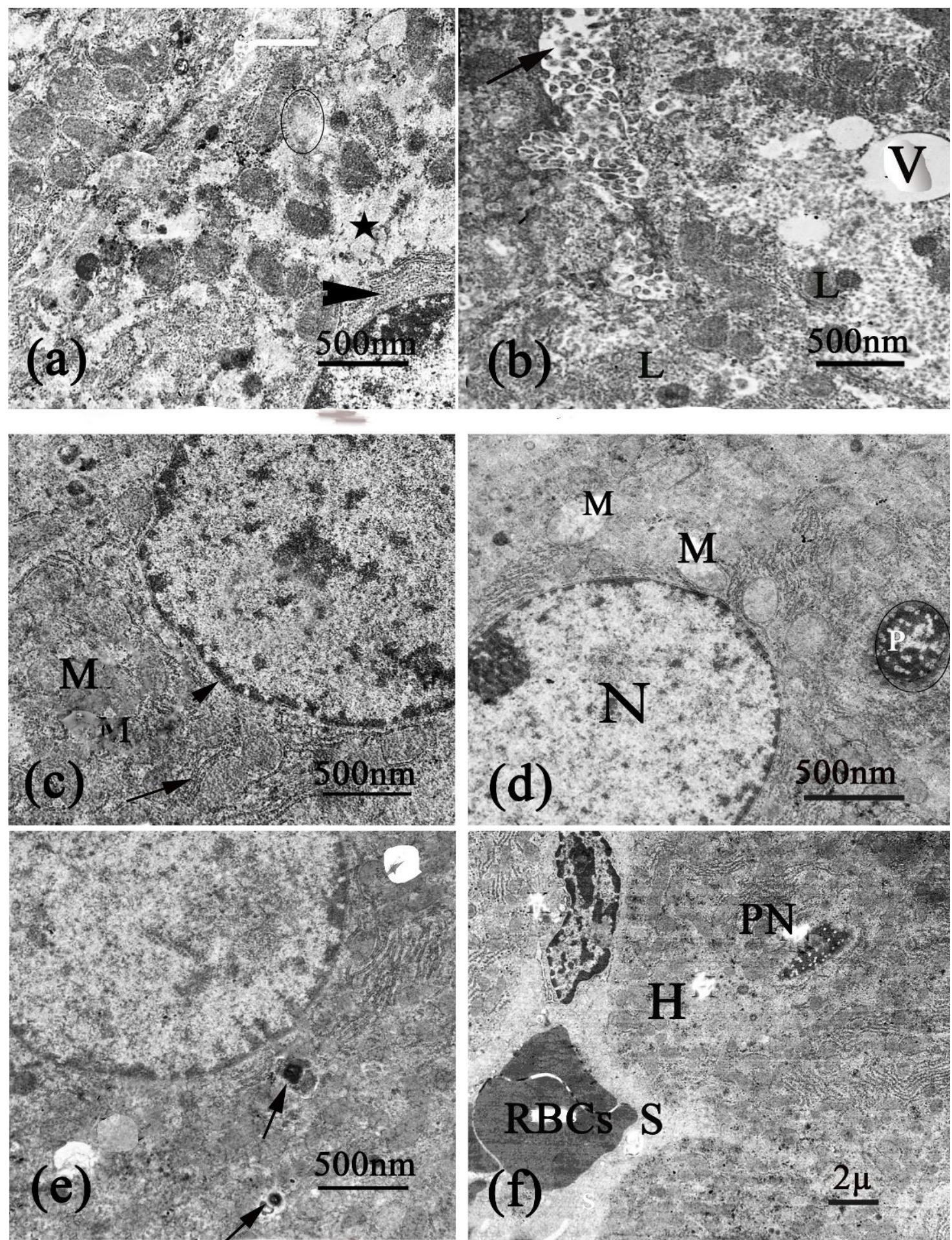

Figure 3: Electron micrographs of hepatocytes of doxorubicin-treated rats for 6 weeks showing: (a) rarified cytoplasm (star), damaged, unparalleled cisternae of RER (head arrow) and enlarged rupture mitochondria (circle) (b) vacuoles (V) and large number of lysosomes (L), broken (not continuous) microvilli (arrow) (c) mild tortuous nuclear envelope (head arrow), degenerated mitochondria (M), and rough endoplasmic reticulum lost most of its ribosomes and its cisternae were unparalleled (arrow), (d) abnormal binucleated hepatocyte, $1^{\text {st }}$ nucleus was large and adequate normal nucleus $(\mathrm{N})$ and the $2^{\text {nd }}$ nucleus was small and pyknotic (P), and swollen mitochondria with destroyed cristae (M), (e) degenerated mitochondria (M) and secondary lysosome (arrow), and (f) part of sinusoids (S) with red blood corpuscles (RBCs) and part of hepatic cell $(\mathrm{H})$ with pyknotic nucleus $(\mathrm{PN})$. 

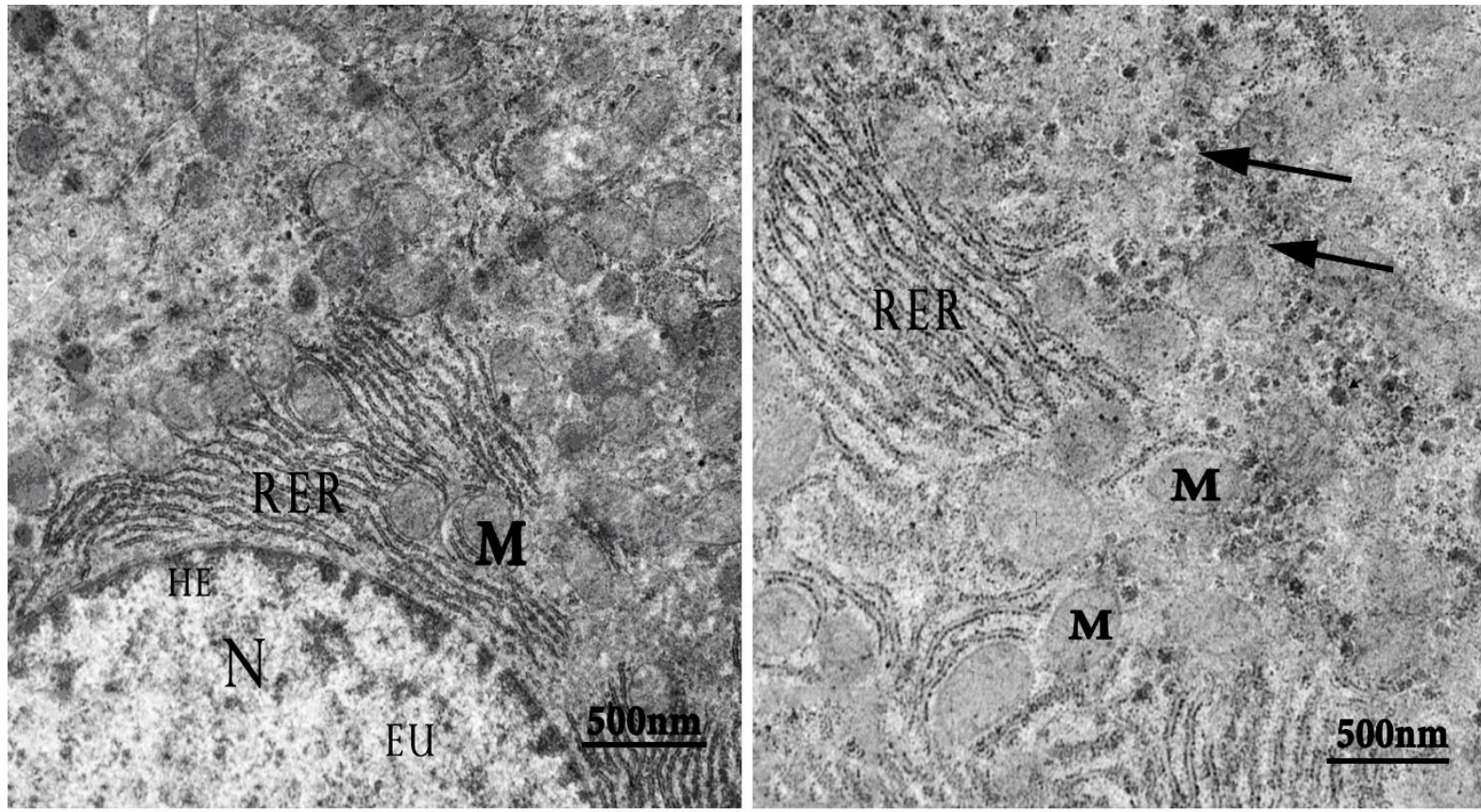

Figure 4: Electron micrographs of hepatocytes of doxorubicin+thyme treated rats for 6 weeks showing (a) normal mitochondria (M), normal nucleus (N) with normal heterochromatin (HE) and euchromatin (EU), normal rough endoplasmic reticulum (RER), and (b) parallel flattened cisternae of RER, normal mitochondria (M), and rosette shape of glycogen granules (arrows).

breaks, and mutation chromosomal aberrations $^{[34]}$. Sakr et al. ${ }^{[35]}$ reported that intraperitoneal injection of doxorubicin caused many histopathological changes including the histological changes in the liver such as congestion of blood vessels, leucocytic infiltration, cytoplasmic vacuolization of the hepatocytes, and fatty infiltration in liver of male albino rat. In addition, Chaudhary et al. ${ }^{[36]}$ found hepatic cords degeneration, vacuolated cells with elliptical shaped nuclei, necrosis, irregular cell membrane, and change in the size of both the hepatocytes and the nuclei in the doxorubicin-treated rats. Chondrou et al.$^{[37]}$ reported that doxorubicin increased micronucleus frequency as identified by chromosome breakage and chromosome delay. It also induced disturbance in chromosome orientation and centrosome duplication and/or separation, leading to aneuploidy ${ }^{[37]}$.

In the current study, the ultrastructure examination of liver sections treated with doxorubicin showed rarified, vacuolated cytoplasm, enlarged ruptured mitochondria, large number of lysosomes, and mild

tortuous nuclear envelope; the rough endoplasmic reticulum lost most of its ribosomes and its cisternae were unparalleled. The ultrastructure observations run in parallel with the histopathological changes found in liver of doxorubicintreated animals in this study. Moreover, these abnormalities may be happened due to the reduction in antioxidant enzymes that recorded in the current study. It was also found that doxorubicin leads to tissue injuries due to imbalance between oxidative stress and the antioxidant defense system ${ }^{[38]}$. The mitochondrial damage caused by doxorubicin returns to its ability to bind to cardiolipin (anchor for cytochrome $\mathrm{c}$ that is necessary for the maximal activity of the adenine nucleotide translocator) and form doxorubicin-cardiolipin complex that prevent cytochrome $\mathrm{c}$ from binding, and thus inhibited oxidative phosphorylation and caused mitochondrial damage ${ }^{[39]}$. Also, doxorubicin may induce mitochondrial damage through overloading iron in the mitochondria ${ }^{[40]}$. Nuclear damage reported in this study may be explained by interference 
of doxorubicin with topoisomerase enzymes as reported previously ${ }^{[41]}$, where the interference by doxorubicin with topoisomerase in cardiomyocytes was the main initiator of the cardiotoxic cascade, resulting in nuclear damage, p53 activation, and downstream inhibition of mitochondrial function, and defect in the mitochondrial biogenesis. In addition, to the above, doxorubicin treatment induces p66Shc protein upregulation specifically in nuclear fractions, leading to the activation of nuclear expression of a forkhead-type transcription factor "FoxO3a", which occurs upstream of target genes for cell death ${ }^{[42]}$. In agreement with the current findings, El-Sayyad et al. ${ }^{[43]}$ found that doxorubicin caused vesiculation of rough endoplasmic reticulum and atrophy of mitochondria, dense collection of macrophages and lymphocytes, as well as fibrocytes with collagenous fibrils manifesting early sign of fibrosis. Condensed chromatin masses and appearance of vacuolization in the cytoplasm were also seen in doxorubicin-treated animals ${ }^{[43]}$.

The importance and wide spread of using herbs in medication comes from their bioactive compounds (secondary metabolites) such as phenolic compounds and flavonoids. Thymus vulgaris, "thyme", is a well-known herb with aromatic characteristics, and it is frequently used because of its antibacterial and antioxidant properties ${ }^{[44]}$. In the present work, thyme oil was proven to interfere with the hazardous effects of doxorubicin. At the level of both histological and ultrastructural studies, the architecture of liver appeared more improved in doxorubicin+thyme group when compared with doxorubicin-treated group. The potential of Thymus vulgaris referred to its content of flavonoids, thymol, carvacrol, eugenol, and aliphatic phenols ${ }^{[30]}$. Carvacrol present in thyme extracts exhibited potent antioxidant activity comparable to the known antioxidants, such as $\alpha$-tocopherol ${ }^{[45]}$. In addition, dietary sources of luteolin from thyme showed antiinflammatory, antioxidant, and anticancer activities, as well as the power to inhibit angiogenesis, induce apoptosis, and prevent carcinogenesis in animal models by inhibiting the topoisomerases I and II and stabilizing $\mathrm{p} 53^{[46]}$. Thyme vulgaris extract approved its ability to reduce oxidative stress after different conditions by preventing the decrease in glutathione and increasing the antioxidant capacity ${ }^{[47]}$. Thyme vulgaris extract reduced the caspase-3 expression and ultimately protected the cells from oxidative stressinduced apoptosis after methotrexate ${ }^{[48]}$. In addition, thymol improves alterations happened in hepatocytes by hydrocortisone ${ }^{[49]}$. Thyme extract also alleviated inflammatory cells infiltration and the liver tissue damage caused by cisplatin in rabbits $^{[50]}$.

In the present study, thymol oil modulated significantly all biochemical changes induced by doxorubicin in rat sera. The action of thyme oil shown in the present work could be due to its ability to enhance the antioxidant defense system. Confirming this conclusion Kozics et $a .^{[51]}$ indicated that the molecular mechanisms responsible for the curative power of Thymus vulgaris against DNA damage in rats induced by hydrogen peroxide and 2,3-dimethoxy-1,4-naphthoquinone was through enhancing SOD activity and elevating GSH level. Thyme essential oil also reduced the activities of the serum AST and ALT in acetaminophen-treated mice ${ }^{[52]}$. Thymol also showed strong alleviative effect against hydrocortisone-induced oxidative stress injury in hepatic tissues of male rats ${ }^{[49]}$. Thyme essential oil reduced the oxidation rate by eliminating free radicals or directing the breakdown of peroxides into stable substances, which cannot promote further oxidation $^{[53]}$.

In conclusion, the current study approved the ability of thyme oil to reduce the harmful effect of doxorubicin on liver architecture. The improvement observed returns to the active biocompounds of thyme oil that have antioxidant properties and thus scavenge the free radicals formed by doxorubicin. 


\section{FUNDING SOURCE DISCLOSURE}

This study did not receive any specific grant from funding agencies in the public, commercial, or not-for-profit sectors.

\section{CONFLICT OF INTEREST}

The authors declare no potential financial conflict of interest.

\section{ACKNOWLEDGMENTS}

The authors dedicate this work to the soul of Prof. Dr. Saber A. Sakr who was supportive and helpful to this work.

\section{REFERENCES}

[1] Bray, F.; Ferlay, J.; Soerjomataram, I. et al. (2018). Global cancer statistics 2018: GLOBOCAN estimates of incidence and mortality worldwide for 36 cancers in 185 countries. CA cancer J Clin, 68(6): 394-424.

[2] Skeel, R. T. (2007). Antineoplastic drugs and biological response modifiers: classification, use, and toxicity of clinically useful agents. In: Handbook of cancer chemotherapy (Skeel, R. T., ed), pp. 693-843. Lippincott Williams \& Wilkins, Philadelphia, PA, USA.

[3] Ritter, J. M.; Lewis, L. D.; Mant, T. G. K. et al. (2008). Textbook of clinical Pharmacology and Therapeutics. CRC press, London, UK.

[4] Shi, Y.; Su, X.; Cui, H. et al. (2019). Combination of quercetin and Adriamycin effectively suppresses the growth of refractory acute leukemia. Oncol lett, 18: 153-160.

[5] Ghannam, M. M.; Al-Otaibi, H. A.; Alanazy, E. S. et al. (2021). Magnetic field potential effects on the doxorubicin therapeutic activity in Ehrlich tumor growth. Saudi J Biol Sci, 28(4): 2566-2574.

[6] Rathos, M. J.; Khanwalkar, H.; Joshi, K. et al. (2013). Potentiation of in vitro and in vivo antitumor efficacy of doxorubicin by cyclin-dependent kinase inhibitor P276-00 in human non-small cell lung cancer cells.
BMC Cancer, 13: 29 (DOI: 10.1186/ 1471-2407-13-29).

[7] Kang, Y.; Wang, W.; Zhao, H. et al. (2017). Assessment of subclinical doxorubicin-induced cardiotoxicity in a rat model by speckle-tracking imaging. Arq Bras Cardiol, 109(2): 132-139.

[8] Ali, N.; Al Asmari, A. F.; Imam, F. et al. (2021). Protective effect of diosmin against doxorubicin-induced nephrotoxicity. Saudi J Biol Sci, (DOI: org/10.1016/j.sjbs.2021.04.030).

[9] Shivakumar, P.; Rani, M. U.; Reddy, A. G. et al. (2012). A study on the toxic effects of doxorubicin on the histology of certain organs. Toxicol Int, 19(3): 241-244.

[10] Manjanatha, M. G.; Bishop, M. E.; Pearce, M. G. et al. (2014). Genotoxicity of doxorubicin in F344 rats by combining the comet assay, flow-cytometric peripheral blood micronucleus test, and pathway-focused gene expression profiling. Environ Mol Mutagen, 55: 24-34.

[11] Lee, K. M.; Lee, I. C.; Kim, S. H. et al. (2012). Melatonin attenuates doxorubicin-induced testicular toxicity in rats. Andrologia, 44: 796-803.

[12] Mohebbati, R.; Jalili-Nik, M.; Paseban, M. et al. (2018). Effects of Zataria multiflora extract and carvacrol on doxorubicin-induced oxidative stress in rat brain. Pharm Sci, 24(3): 187-192.

[13] Kocahan, S.; Dogan, Z.; Erdemli, E. et al. (2017). Protective effect of quercetin against oxidative stressinduced toxicity associated with doxorubicin and cyclophosphamide in rat kidney and liver tissue. Iran J kidney Dis, 11(2): 124-131.

[14] Boon, H. and Smith, M. (2004). The complete natural medicine guide to the 50 most common medicinal herbs. Robert Rose Inc., Toronto, Canada.

[15] Kulisic, T.; Radonic, A. and Milos, M. (2005). Antioxidant properties of 
thyme (Thymus vulgaris L.) and wild thyme (Thymus serpyllum L.) essential oils. Ital J Food Sci, 17(3): 315- 324.

[16] Juhás, Š.; Bujňáková, D.; Rehák, P. et al. (2008). Anti-inflammatory effects of thyme essential oil in mice. Acta Vet Brno, 77(3): 327-334.

[17] Boskovic, M.; Zdravkovic, N.; Ivanovic, J. et al. (2015). Antimicrobial activity of thyme (Tymus vulgaris) and oregano (Origanum vulgare) essential oils against some food-borne microorganisms. Procedia Food Sci, 5: 1821.

[18] Sertel, S.; Eichhorn, T.; Plinkert, P. K. et al. (2011). Cytotoxicity of Thymus vulgaris essential oil towards human oral cavity squamous cell carcinoma. Anticancer Res, 31(1): 8187.

[19] Schmidt, E.; Wanner, J.; Höferl, M. et al. (2012). Chemical composition, olfactory analysis and antibacterial activity of Thymus vulgaris chemotypes geraniol, 4-thujanol/terpinen-4ol, thymol and linalool cultivated in southern France. Nat Prod Commun, 7(8): 1095-1098.

[20] Bayomy, M. F. F.; Sakr, S. A. and Gendia S. E. M. (2016). Biochemical and histological studies on the possible protective impact of the herb basil (Ocimum basilicum) on adriamycin induced toxicity in rats. I. Influence on the liver. JBAAR, 2(9): 634-640.

[21] Nada, A. S. (2013). Modulating efficacy of thyme oil in rats exposed to $\gamma$-radiation. J Radiat Res Appl Sci, 6(1): 35-52.

[22] Lillie R. D. and Fullmer H. M. (1976). Histopathological Technigues and Practical Histochemistry. McGraw Hill, New York, NY, USA.

[23] Karnovsky M. J. (1965). A formaldehyde-glutaraldehyde fixative of high osmolality for use in electron microscopy. J Cell Biol, 27: 137-138.

[24] Reitman, S. and Frankel, S. (1957). A colorimetric method for the determination of serum glutamic oxalacetic and glutamic pyruvic transaminases. Amer J Clin Pathol, 28(1): 56-63.

[25] Esterbauer, H. and Cheeseman, K. H. (1990). Determination of aldehydic lipid peroxidation products: malonaldehyde and 4-hydroxynonenal. Methods Enzymol, 186: $407-$ 421.

[26] Masayasu, M. and Hiroshi, Y. (1979). A simplified assay method of superoxide dismutase activity for clinical use. Clin Chim Acta, 92(3): 337-342.

[27] Goth, L. (1991). A simple method for determination of serum catalase activity and revision of reference range. Clin Chim Acta, 196(2-3): 143151.

[28] Injac, R.; Perse, M.; Obermajer, N. et al. (2008). Potential hepatoprotective effects of fullerenol $\mathrm{C} 60(\mathrm{OH}) 24$ in doxorubicin-induced hepatotoxicity in rats with mammary carcinomas. Biomaterials, 29(24-25): 3451-3460.

[29] Sakr, S. A. and Abo-El-Yazid, S. M. (2012). Effect of fenugreek extract on Adriamycin-induced hepatotoxicity and oxidative stress in albino rats. Toxicol Ind Health, 28(10): 876-885.

[30] Sobhy, H. M.; Hassanen, N. H. M. and Ahmed, M. A. I. (2020). Hepatoprotective activities of thyme (Thymus vulgaris L.) in rats suffering from obesity. Egypt J Chem, 63(12): 5087-5101.

[31] Hozayen, W. G.; Abou Seif, H. S. and Amin, S. (2014). Protective effects of ruitn and/or hesperidin against doxorubicin-induced hepatotoxicity. Int J Clin Nutr, 2: 11-17.

[32] Mokni, M.; Hamlaoui, S.; Kadri, S. et al. (2015). Efficacy of grape seed and skin extract against doxorubicininduced oxidative stress in rat liver. Pak J Pharm Sci, 28(6): 1971-1978.

[33] Yagmurca, M.; Erdogan, H.; Iraz, M. et al. (2004). Caffeic acid 
phenethyl ester as a protective agent against doxorubicin nephrotoxicity in rats. Clin Chim Acta, 348(1-2): 27-34.

[34] Cebula, T. A. (1986). Genetic and physiological modulation of anthracycline-induced mutagenesis in Salmonella typhimurium. Environ Mutagen, 8(5): 675-692.

[35] Sakr, S. A.; Mahran, H. A. and Lamfon, H. A. (2011). Protective effect of ginger (Zingiber officinale) on Adriamycin-induced hepatotoxicity in albino rats. J Med Plant Res, 5(1): 133-140.

[36] Chaudhary, D.; Khatiwada, S.; Sah, S. K. et al. (2016). Effect of doxorubicin on histomorphology of liver of wistar albino rats. J Pharm Pharmacol, 4(4): 186-190.

[37] Chondrou, V.; Trochoutsou, K.; Panayides, A. et al. (2018). Combined study on clastogenic, aneugenic and apoptotic properties of doxorubicin in human cells in vitro. J Biol Res (Thessalon), 25: 17 (DOI: 10.1186 /s40709-018-0089-z).

[38] Prasanna, P. L.; Renu, K. and Gopalakrishnan, A. V. (2020). New molecular and biochemical insights of doxorubicin-induced hepatotoxicity. Life Sci, 250: 117599 (DOI: 10.1016/j.lfs.2020.117599).

[39] Goormaghtigh, E.; Huart, P.; Brasseur, R. et al. (1986). Mechanism of inhibition of mitochondrial enzymatic complex I-III by adriamycin derivatives. Biochim Biophys Acta, 861(1): 83-94.

[40] Wallace, K. B.; Sardão, V. A. and Oliveira, P. J. (2020). Mitochondrial determinants of doxorubicin-induced cardiomyopathy. Cir Res, 126(7): 926941.

[41] Zhang, C.; Feng, Y.; Qu, S. et al. (2011). Resveratrol attenuates doxorubicin-induced cardiomyocyte apoptosis in mice through SIRT1mediated deacetylation of p53. Cardiovasc Res, 90(3): 538-545.
[42] Sampaio, S. F.; Branco, A. F.; Wojtala, A. et al. (2016). p66Shc signaling is involved in stress responses elicited by anthracycline treatment of rat cardiomyoblasts. Arch Toxicol, 90(7): 1669-1684.

[43] El-Sayyad, H. I.; Ismail, M. F.; Shalaby, F. M. et al. (2009). Histopathological effects of cisplatin, doxorubicin and 5-flurouracil (5-FU) on the liver of male albino rats. Int $\mathbf{J}$ Biol Sci, 5(5): 466-473.

[44] Aljabeili, H. S.; Barakat, H. and Abdel-Rahman, H. A. (2018). Chemical composition, antibacterial and antioxidant activities of thyme essential oil (Thymus vulgaris). Food Nut Sci, 9(5): 433-446.

[45] Lee, K. G. and Shibamoto, T. (2002). Determination of antioxidant potential of volatile extracts isolated from various herbs spices. J Agric Food Chem, 50(17): 4947-4952.

[46] Lopez-Lazaro, M. (2009). Distribution and biological activities of the flavonoid luteolin. Mini Rev Med Chem, 9(1): 31-59.

[47] Meydan, S.; Esrefoglu, M.; Selek, S. et al. (2019). Protective effects of caffeic acid phenethyl ester and thymoquinone on toluene induced liver toxicity. Biotech Histochem, 94(4): 277-282.

[48] Omar, N.; El-Kot, A. A. and Khalifa, E. I. (2021). Protective role of thyme leave extract on methotrexate-induced histological and immunohistochemical changes in testes of rats. Egypt J Hosp Med, 83: 1230-1238.

[49] Aboelwafa, H. R. and Yousef, H. N. (2015). The ameliorative effect of thymol against hydrocortisone-induced hepatic oxidative stress injury in adult male rats. Biochem Cell Biol, 93(4): 282-289.

[50] Abu-Raghif, A. R.; Sahib, A. S. and Hasan, S. A. (2016). Hepatoprotective effects of thyme extract in cisplatininduced liver toxicity in rabbits. Der Pharm Lett, 8 (19): 24-28. 
[51] Kozics, K.; Klusova, V.; Srančikova, A. et al. (2013). Effects of Salvia officinalis and Thymus vulgaris on oxidant-induced DNA damage and antioxidant status in HepG2 cells. Food Chem, 141(3): 2198-2206.

[52] Grespan, R.; Aguiar, R. P.; Giubilei, F. N. et al. (2014). Hepatoprotective effect of pretreatment with Thymus vulgaris essential oil in experimental model of acetaminophen-induced injury. Evid Based Complement Alternat Med, 2014: 954136 (DOI: 10.1155/2014/ 954136).

[53] Osman, N. N.; Balamash, K. S. A. and Aljedaani, M. S. (2019). Impact of peppermint and thyme in ameliorating cardiac and hepatic disorders induced by feeding rats repeatedly heated fried oil. Int J Pharm Phytopharmacological Res, 9(6): 10-20.

\section{How to cite this article:}

Kandil, E. H.; Okdah, Y. A. and Moselhy, A. G. (2021). Effect of thyme oil on doxorubicin-induced hepatotoxicity in female albino rats: histological, ultrastructural, and biochemical studies. Egyptian Journal of Zoology, 76: 76-90 (DOI: 10.21608/ejz.2021.84202.1062). 


\title{
تأثير زيت الزعتر على السُمية الكبدية المحدثة بالدوكسوروبيسين في إناث الجِرذان المهقاء: دراسات نسيجية، وتركيبية دقيقة، وبيوكيميائية
}

\author{
إيمان حسني قنديل، يسري علي عقدة، آيات جمال مصيلحي \\ قسم علم الحيوان، كلية العلوم، جامعة المنوفية، المنوفية، جمهورية مصر العربية
}

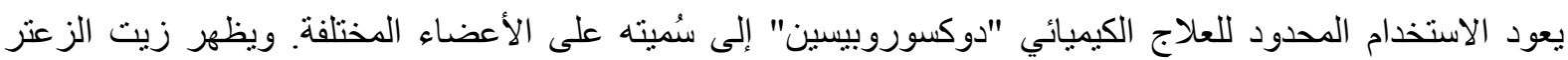

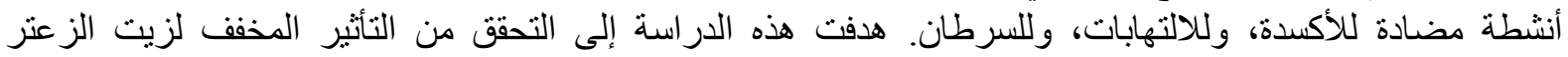

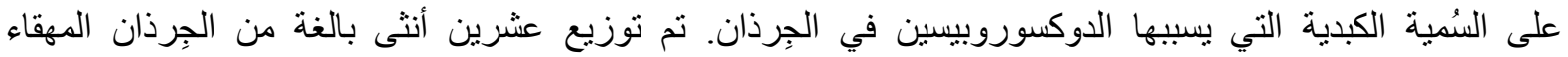
(Rattus norvegicus)

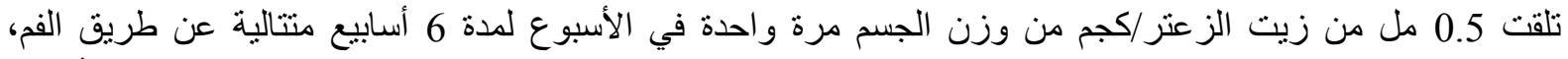

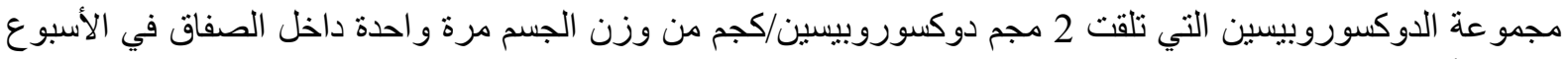

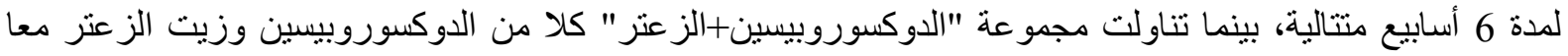

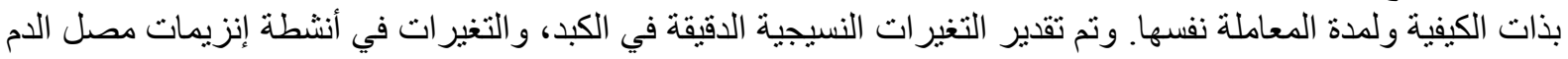

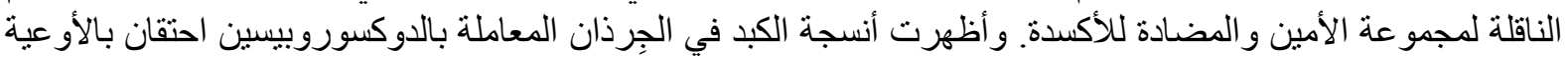

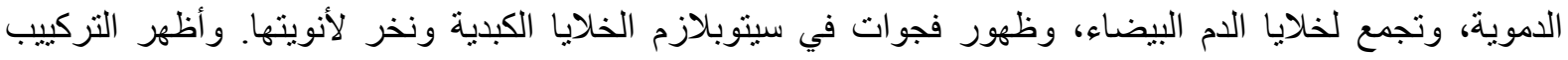

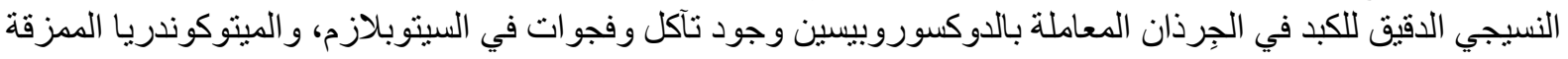

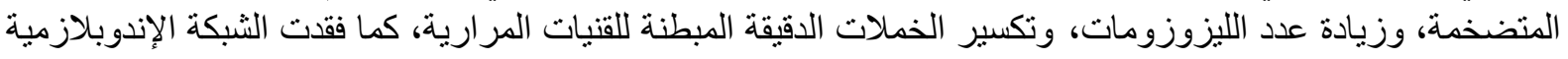

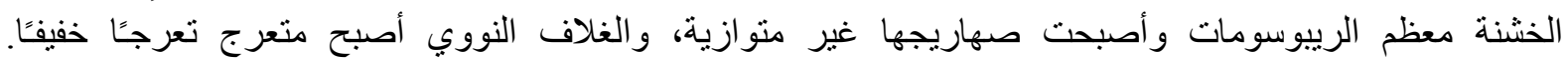
وزادت أنشطة الإنزيمين "AST و ALT" ومستوى الأكسدة الدهنية بشكل كبير، بينما انخفضت النئ أنشطة الإنزيمين

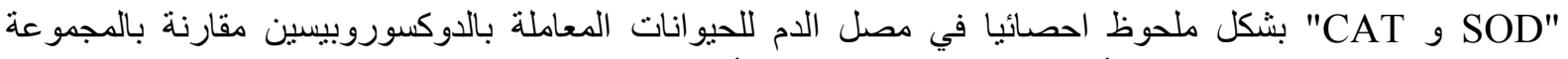

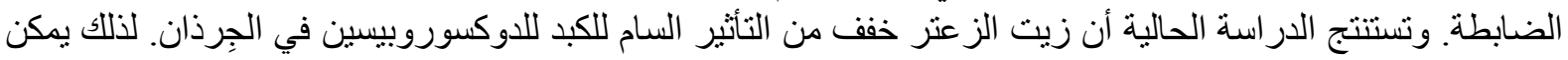
استخدام زيت الزعتر كعلاج مساعد لتقليل سُمية الدوكسور التروبيسين. 